\title{
Time-Varying Risk Premia in the Foreign Currency Futures Basis
}

\author{
Christopher F. Baum and John Barkoulas $\$$
}

January, 1996

\begin{abstract}
Significant time-varying risk premia exist in the foreign currency futures basis, and these risk premia are meaningfully correlated with common macroeconomic risk factors from equity and bond markets. The stock index dividend yield and the bond default and term spreads in the U.S. markets help forecast the risk premium component of the foreign currency futures basis. The specific source of risk matters, but the relationships are robust across currencies. The currency futures basis is positively associated with the dividend yield and negatively associated with the spread variables. These correlations cannot be attributed to the expected spot price change component of the currency futures basis, thus establishing the presence of a timevarying risk premium component in the currency futures basis.
\end{abstract}




\section{Introduction}

The presence of a time-varying risk premium (TVRP) was confirmed in a variety of futures markets for commodities by Bailey and Chan (1993), who found that a small number of macroeconomic risk factors from equities and bond markets are meaningfully related to futures basis movements. Hodrick and Srivastava (1987), Bessembinder and Chan (1992), and McCurdy and Morgan (1992) have established the presence of risk premia in currency futures pricing, while Hsieh (1993) found evidence to the contrary. Contributing to this literature, this paper follows the approach of Bailey and Chan and investigates the presence of risk premia in the currency futures basis in two steps. In the first step, the currency futures basis, or alternatively the interest-rate differential by virtue of the covered interest parity relationship, is regressed upon proxies for systematic risk in the economy. Having established significant correlations in the first step, the realized spot-price change is regressed upon the same risk proxies in the second step, which allows inferences to be drawn regarding the presence of risk premia in the currency futures basis. In addition, the low-frequency properties of the currency futures basis series are rigorously analyzed and their volatility process is modeled via GARCH. Preliminary evidence regarding the presence of common elements in basis variation across currencies is obtained from principal component analysis. Proxies for systematic risk in the U.S. financial markets help explain comovements among the currency futures basis. The specific source of risk matters, with a stronger association with the bond market risk factors. These associations cannot be attributed to the expected spot price change component of the currency futures basis, and thus indicate the presence of time-varying risk premia in the currency futures basis.

The covered interest parity (CIP) condition states that, in the absence of riskless arbitrage opportunities, the differential between (logarithms of) domestic and foreign interest rates on securities of a given tenor must equal the basis of a forward contract of that same tenor-that is, the differential between (logarithms of) forward and spot prices for a quantity of the foreign currency. The price of an identically timed futures contract on the foreign currency should also obey this 
relation if daily mark-to-market effects are small. In a foreign currency market which exhibits sufficient liquidity, the interest rate differential and the futures basis may thus be used interchangeably to study the characteristics of the relation. While CIP governs the evolution of the levels of spot and futures prices vis-à-vis interest rates, it does not preclude significant time variation in the basis series, nor in interest rate differentials. Identification of factors influencing such time variation should improve understanding of the comovements of risk factors across financial markets.

The plan of the paper is as follows. Section II contains a brief review of the literature and the analytical structure. Section III describes the data set and econometric methodology. Empirical findings are presented in Section IV, with a summary and conclusions in Section V.

\section{Literature Review}

For many commodities and financial instruments, movements in the futures basis reflect variations in the cost-of-carry and returns from maintaining a position in the underlying commodity. When major foreign currencies are considered, the covered interest parity (CIP) relation is presumed to hold so as to preclude riskless arbitrage opportunities. The CIP relationship is reasonably well supported by the data (Frenkel and Levich (1975, 1977), Taylor (1987, 1989), Frankel (1991)). Under the CIP condition, the foreign currency futures basis is necessarily determined by the relative interest rates in domestic and foreign markets, with observed discrepancies attributed to transactions costs and errors in measurement. ${ }^{1}$ The CIP condition may be stated as

$$
F_{t}-S_{t}=R_{t}-R_{t}^{*}
$$

where $F_{t}$ is the $\log$ of the futures price for delivery at time $t+1$, as observed at time $t, S_{t}$ is the log

of the spot rate at time $t, R_{t}$ is the $\log$ of the one-period domestic interest rate, and $R_{t}^{*}$ is the $\log$ of the one-period foreign interest rate. ${ }^{2}$ McCallum notes that due to covered interest parity, these two 
variables-the interest rate differential and the futures basis-"should be so highly correlated that they could be used interchangeably, with the choice made on the basis of data availability and convenience" (1994, p. 112). ${ }^{3}$ With this in mind, an examination of the behavior of the currency futures basis and its systematic relation to risk factors should also be considered an examination of relative interest rates' linkages to those same factors.

Alternatively, the currency futures basis can also be expressed as:

$$
F_{t}-S_{t}=\left\{F_{t}-E_{t}\left[S_{t+1} \mid \Omega_{t}\right]\right\}+E_{t}\left[\left(S_{t+1}-S_{t}\right) \mid \Omega_{t}\right]
$$

where $E_{t}$ is the expectations operator, $\Omega_{t}$ is the information set at time $t$, and $S_{t+1}$ is the $\log$ of the spot rate at time $t+1 . .^{4}$ The first bracketed term represents an expected premium, while the second term is an expected forecast error. Movements in the foreign currency futures basis may thus be informative about the expectational error in spot rates (which under risk neutrality would be completely responsible for changes in the basis) and the presence of possibly time-varying risk premia. In the empirical analysis, the observed basis for several currencies is related to a set of common macroeconomic risk factors. The decomposition in (2) is then applied to determine to what degree the observed relationship reflects the influence of expectational errors versus that of risk premia.

The identification of common factors which might be expected to influence the workings of currency markets is based on recent findings by Bailey and Chan (1993), who associated macroeconomic risks common to all asset markets to variations in the basis of twenty-two physical commodities. They found that after accounting for the effect of interest rates, common basis variations were correlated with observed proxies for systematic risk in the stock and bond markets. Their stock market variable is the dividend yield of the SP500 portfolio. Their bond market variables are two term-structure factors, a default premium and a term premium. The rationale for including the above variables in the futures basis equation derives from the studies by Keim and Stambaugh (1986), Fama and French (1988a, b, 1993) and Chen (1991) which have shown that the variables in 
question possess significant forecast power for equity and bond returns. More specifically, these variables are negatively related to business conditions and positively related to expected returns in the equity and bond markets. The countercyclical variation of expected returns can be explained on the basis of consumption smoothing. When business conditions are poor, income is low and expected returns on stocks and bonds must be high to induce substitution from consumption to investment. When times are good and income is high, the market clears at lower levels of expected returns. This explanation is consistent with modern asset pricing models but it is hardly unique. An alternative explanation could be attributed to changes in the level of riskiness of stocks and bonds with business conditions. Bailey and Chan showed that the associations of the stock and bond market risk factors to the commodity futures basis are largely due to the presence of risk premia, rather than spot price forecasts, in the basis.

\section{Data and Econometric Methodology}

\section{Data}

The data for futures prices are beginning-of-month U. S. dollar opening bid prices in the International Monetary Market (IMM) of the Chicago Mercantile Exchange for the Canadian dollar (CD), Deutsche mark (DM), British pound (BP), Swiss franc (SF), and Japanese yen (JY) for various maturities. Spot currency rates are beginning-of-month opening bid prices and were provided by Data Resources, Incorporated. The sample period is from January 1982 to December 1991 for a total of 120 observations. In matching the data, contracts are assumed to mature on the first trading day of the delivery month; maturity ranges are used rather than specific maturities. A range of two to four months is used: three-month futures contacts when available and a two- to fourmonth contract otherwise.

The proxy for the risk premium in the stock market is the dividend yield, DY, which is constructed by dividing total dividends paid on the SP500 portfolio during period $t$ by the value of the SP500 portfolio at the end of period $t$. The proxies for risk premia in bond markets are a default 
premium and a term premium which capture most of the variation in the returns on government and corporate bond portfolios. The default spread, DEF, is defined as the net return from investing in long-term corporate bonds rather than long-term government bonds of equal maturity:

$$
\frac{1+R_{C}}{1+R_{g}}-1
$$

where,

$$
\begin{aligned}
& R_{c}=\text { total monthly return on long-term corporate bonds, and } \\
& R_{g}=\text { total monthly return on long-term government bonds. }
\end{aligned}
$$

The corporate bond returns are based on the Salomon Brothers Long-Term High-Grade Corporate Bond Index which includes nearly all Aaa- and Aa-rated bonds. Government bond returns are based on a one-bond portfolio with a term of approximately 20 years, and are calculated as the relative change in the flat or and-interest price. 5

The term premium, TERM, is the premium investors demand for holding long-term government bonds instead of U. S. Treasury bills, given by

$$
\frac{1+R_{g}}{1+R_{f}}-1
$$

where,

$$
R_{f}=\text { total return on 30-day Treasury bills. }
$$

Each month a one-bill portfolio containing the shortest-term bill having not less than one month to maturity is constructed. The total return on the bill is the month-end price divided by the previous month-end price, minus one.

The stock and bond market variables are obtained from CITIBASE and Ibbotson Associates, respectively. 


\section{Econometric Methodology}

Many financial time series exhibit volatility clustering so that large changes tend to be followed by large changes of either sign and periods of tranquility alternate with periods of high volatility. Such time series properties can be well modeled by Generalized Autoregressive Conditional Heteroscedastic (GARCH) models. Let $i=1, \ldots, 5$ represent the $\mathrm{CD}, \mathrm{DM}, \mathrm{BP}, \mathrm{SF}$, and JY currency rates versus the U.S. dollar, respectively. Consider the following GARCH $(1,1)$ model for the currency futures basis:

$$
\begin{aligned}
& F B_{i, t}=X_{t} \beta_{i}+\varepsilon_{i, t} \\
& \left(\varepsilon_{i, t} \mid \Omega_{t}\right) \sim N\left(0, h_{i, t}\right) \\
& h_{i, t}=\omega_{i}+\gamma_{i i} \varepsilon_{i, t-1}^{2}+\delta_{i i} h_{i, t-1}
\end{aligned}
$$

where $F B_{i, t}$ is the futures basis for currency $i, i=1, \ldots, 5, X_{t} \beta_{i}$ is the conditional mean representing the effects of the exogenous variables, $\varepsilon_{i, t}$ is a random disturbance, and $t$ is the calendar date. The $\operatorname{GARCH}(1,1)$ specification has proven to be an adequate representation for most financial time series. For each currency $i=1, \ldots, 5$, the corresponding set of parameter values $\left(\beta_{i}, \omega_{i}, \gamma_{i i}, \delta_{i i}\right)$ is estimated by maximizing the log-likelihood function

$$
L=\sum_{t=1}^{T} \ell_{t}
$$

where the typical log likelihood term for time $t$, ignoring constants, takes the form

$$
\ell_{t}=-0.5 \log h_{i, t}-0.5 \frac{\left(\varepsilon_{i, t}\right)^{2}}{h_{i, t}}
$$

The parameter estimates are asymptotically normal. The Berndt, Hall, Hall, and Hausman (1974) algorithm is used to maximize the log likelihood function in (4). 


\section{Empirical Results}

\section{Preliminary Data Analysis}

Figure 1 graphs the futures basis for each currency, which appear to exhibit similar behavior over time. The futures basis for the DM, SF, and JY move closely together while for the CD and BP the pattern is very similar except for a scale factor. Table I provides summary statistics for the currency futures basis. The mean futures basis is statistically different from zero for all currencies, positive for the DM, SF, and JY, and negative for the CD and BP. The standard deviation of the basis is lowest for the $\mathrm{CD}, 0.4 \%$, and highest for the $\mathrm{SF}, 1.0 \%$. The futures basis series vary in an autocorrelated way. The first-order autocorrelations are greater than 0.64 and the persistence is substantial and positive but declining geometrically over time. Figure 2 plots the correlograms for up to forty-eighth order serial correlation in the currency futures basis and indicates that the autocorrelation function is very similar across currency futures basis. Formal evidence of serial dependence in the basis series is presented in Table II. The Box-Pierce test, adjusted for the presence of conditional heteroscedasticity (Diebold, 1986), indicates substantial serial correlation in all basis series. Also, there is evidence of nonlinear dependence in the data as manifested by the significant test statistics for Engle's (1982) test for autoregressive conditional heteroscedasticity (ARCH).

The presence of persistence in the currency futures basis raises the issue of nonstationarity in the data. Previous studies on commodity futures basis have relied on the behavior of the autocorrelation function of the futures basis to diagnose mean reversion. Low-frequency properties of the currency basis series are rigorously investigated since the regression methods used later assume stationarity of the data. Two unit root tests are utilized: the Phillips-Perron test (PP) (Phillips (1987), Phillips and Perron (1986)), and the Kwiatkowski-Phillips-Schmidt-Shinn test (KPSS) (Kwiatkowski et al. (1992)). In contrast to the PP test (as well as other standard unit root tests) in which the null hypothesis is nonstationarity (existence of a unit root), the KPSS test assumes stationarity under the null. Used together, these two tests can provide robust evidence with 
respect to the integration order of a series. The combined use of the PP test and the KPSS test for a particular series produces the following alternatives:

(i) Rejection by the PP test and failure to reject by the KPSS test provides evidence in favor of wide-sense stationarity: the series is $I(0)$.

(ii) Failure to reject by the PP test and rejection by the KPSS test provides evidence that the series contains a unit root: the series is $I(1)$.

(iii) Failure to reject by both PP and KPSS tests shows that the data are not sufficiently informative with respect to the low-frequency properties of the series; and

(iv) Rejection by both PP and KPSS tests suggests that the series is not well represented as either $I(1)$ or $I(0)$ and alternative parameterizations need to be considered.

Tables III and IV present the results from the PP and KPSS tests, respectively, for the currency futures basis series as well as for the other series used in the estimation process. The PP tests indicate rejection of the unit-root null hypothesis while the KPSS tests indicate, in general, failure to reject stationarity in all basis series. Therefore, the evidence strongly points toward stationarity in all currency basis series, which was indicated by the declining structure in the autocorrelation function for each currency futures basis. Spot and futures currency rates form a cointegrating system with cointegrating vector $(1,-1)$.

With respect to the degree of smoothness of the remaining series, the evidence generally points toward stationarity (a graph of DY is presented in Figure 3 while Figure 4 graphs DEF and TERM). For the DY, the PP test fails to reject the unit-root null hypothesis while the KPSS test rejects the stationarity hypothesis, suggesting that the series is integrated of order one. It must be noted, however, that the PP test has low power against the alternative of integration order slightly less than one especially in small samples as is the case here. Although it is difficult to make reliable inferences about the stationarity of the stock market variable, it is assumed stationary for purposes of analysis. Keim and Stambaugh (1986) assumed stationarity for DY for the same reasons. Finally, the bond market variables DEF and TERM appear to be stationary since the PP test strongly rejects the unit-root null while the KPSS test fails to reject the null hypothesis of stationarity. 
Prior to formal statistical testing of the determinants of the currency futures basis, preliminary evidence suggesting the presence of common elements in the basis variation across currencies is presented in Table $\mathrm{V}$, which contains contemporaneous correlations among currency futures basis series. Consistent with Figure 1, the correlations are positive and large in value, hinting to strong comovement in the currency basis series over time. The highest correlation is between the basis for the DM and SF, 0.934, and the lowest between the CD and the JY, 0.375. The mean of these ten correlations is 0.686 . A principal component analysis of the covariance matrix of the currency futures basis is performed to extract evidence on common factors. Final communality estimates $\left(h^{2}\right)$, which represent the proportion of the basis variance explained by common factors, for each currency are presented in Table VI. The results suggest that one factor can explain quite a bit of the variation in the futures basis, especially for the DM, BP, and SF. Admitting one additional factor sharply raises the communality estimate for the $\mathrm{CD}$ and to a lesser extent for the other currency futures basis. These estimates indicate that two common factors, or latent variables, can explain a large part of the variation in the currency futures basis, ranging from $64.7 \%$ for the CD to 93.2\% for the SF. Based on this evidence, the common factor model appears to fit the system of currency futures basis adequately. These common factors are now proxied with variables which have been shown to account for systematic risks in the economy.

\section{Systematic Risk and Currency Basis Variation}

This section explains common basis variation in foreign currencies based on ex ante risk premiums common to all financial markets in the domestic economy. As mentioned earlier, economy-wide risks in the economy are proxied with observed yields from the U.S. stock and bond markets. The stock market variable is the dividend yield, DY, and the bond market variables are the bond default spread, DEF, and term spread, TERM. The argument for including risk proxies for only the U.S. economy is based on evidence by Harvey and Huang (1991) and Bollerslev and Engle (1993) that U.S. macroeconomic news dominates the effects of news in European markets for U.S.European rates. 
The following ARMAX-GARCH $(1,1)$ model is estimated for the futures basis for each currency:

$$
\begin{aligned}
& 100 \cdot\left(F_{i, t}-S_{i, t}\right) / S_{i, t}=\alpha_{i 0}+\alpha_{i 1} D Y_{t-1}+\alpha_{i 2} D E F_{t-1}+\alpha_{i 3} \text { TERM }_{t-1}+\varepsilon_{i, t} \\
& \varepsilon_{i, t}=\beta_{i}(L) \varepsilon_{i, t}+\gamma_{i}(L) u_{i, t}, \beta_{i}(L)=\sum_{l=1}^{p} \beta_{i l} L^{l}, \gamma_{i}(L)=\sum_{l=1}^{q} \gamma_{i l} L^{l} \\
& \operatorname{Var}\left(u_{i, t} \mid \Omega_{t}\right) \equiv \sigma_{i, t}^{2}=\omega_{i}+\delta_{i i} u_{i, t-1}^{2}+\varsigma_{i i} \sigma_{i, t-1}^{2}
\end{aligned}
$$

where $L$ is the lag operator. ${ }^{6}$ Since the currency futures basis is measured at the beginning of the month, the explanatory variables are lagged once to indicate conditions prevailing in the financial markets as of the previous month-end. An autoregressive-moving average (ARMA) model is fit to the residuals in each futures basis equation in order to properly account for serial correlation. The order of the ARMA model is chosen by the Schwartz information criterion. The selected orders of the ARMA model are $(6,4),(3,3),(3,3),(5,5)$, and $(3,3)$ for $i=1, \ldots, 5$, respectively.

Table VII reports the results from the model in (6) and indicates that the estimated slope coefficients are generally nonzero. Proxies for the U.S. stock and bond market risk factors are systematically associated with the futures basis across currencies and possess significant explanatory power. ${ }^{7}$ The relationship appears to be qualitatively different for the stock market variable as opposed to the bond market variables but the associations are generally stable in sign across currencies. The coefficient of the lagged SP500 dividend yield is statistically significant in all currency futures basis equations except that for the JY. The association is positive except for the CD futures basis equation where DY enters negatively. The bond market variables, DEF and TERM, enter significantly in the basis equations for all currencies and take a negative sign with the exception of the coefficient estimate of the DEF variable in the BP equation, which is positive.

This evidence establishes a strong association between the foreign currency futures basis, or, alternatively, interest rate differentials, and proxies for systematic risk in the U.S. economy. The forecasting ability of the proxies used is robust across currencies, reinforcing the belief that they 
reflect the conditioning information set used by investors. The specific source of risk (stock versus bond market) matters, with the relationship being positive (negative) for the stock (bond) market risk factors. This differential response of currency futures basis to stock and bond market risk factors awaits explanation. These results contrast with those in Bailey and Chan (1993), which suggest a uniformly positive association of futures basis for commodities to stock and bond market risk factors. However, the results resemble those in Bessembinder and Chan (1992), who found that currency futures returns were related positively to the dividend yield and negatively to the bond spread (except for the JY).

The estimated models for the futures basis across currencies appear to be properly specified on the basis of residual diagnostic tests. Time dependence in the second moments (conditional heteroscedasticity) is a property of all currency futures basis series. Tests for the presence of integrated conditional variances (IGARCH) were also performed by applying the PP and KPSS tests on the conditional variance series. Both statistics appear to reject the hypothesis of integrated variances at the 5\% level for the CD, DM, BP, and JY. Given the presence of IGARCH in the spot and futures currency rates established in previous studies, this result indicates that the spot and futures rates for these four currencies are copersistent, in the sense of Bollerslev and Engle (1993), with copersistence vector $(1,-1){ }^{8}$ For the futures basis for these currencies shocks to volatility have a finite duration and the unconditional variance is finite.

\section{Risk Premia versus Spot Forecast Error}

Does the importance of equity and bond market factors in explaining common variation in currency futures basis necessarily substantiate the presence of a time-varying risk premium? After all, the systematic factors could pick up the expected spot price component of the basis $\left(E_{t} S_{t+1}-S_{t}\right)$ in equation (2) rather than the risk premium component represented by $\left(F_{t}-E_{t} S_{t+1}\right)$. It must be noted that the interest rate differential does not have a natural decomposition as in (2). It is the futures basis for any commodity or financial instrument that has such a representation. Therefore, relationships regarding the futures basis are investigated via equation (2). 
To answer the question of whether the systematic relationship between currency futures basis and stock and bond market risk factors picks up variation in time-varying risk premia, the realized spot forecast error for each basis series is regressed upon the stock and bond market risk factors. The residuals from this regression are modeled as an $\operatorname{ARMA}(p, q)-\operatorname{GARCH}(1,1)$ process to account for dependency in the first and second moments, yielding the following regression for each currency $i=1, \ldots, 5$ :

$$
\begin{aligned}
& 100 \cdot\left(S_{i, t+1}-S_{i, t}\right) / S_{i, t}=\vartheta_{i 0}+\vartheta_{i 1} D Y_{t-1}+\vartheta_{i 2} D E F_{t-1}+\vartheta_{i 3} \text { TERM }_{t-1}+\eta_{i, t} \\
& \eta_{i, t}=\lambda_{i}(L) \eta_{i, t}+\mu_{i}(L) v_{i, t}, \lambda_{i}(L)=\sum_{l=1}^{p} \lambda_{i l} L^{l}, \mu_{i}(L)=\sum_{l=1}^{q} \mu_{i l} L^{l} \\
& \operatorname{Var}\left(v_{i, t} \mid \Omega_{t}\right) \equiv \sigma_{i, t}^{2}=o_{i}+\pi_{i i} u_{i, t-1}^{2}+\tau_{i i} \sigma_{i, t-1}^{2}
\end{aligned}
$$

If the coefficients for the instruments for the economy-wide risk factors are statistically insignificant in equation (7), this would provide evidence that the basis regressions are detecting time variation in risk premia, as opposed to time-varying expected spot price changes. It is equation (7) which allows inferences to be drawn regarding the presence of time-varying risk premia in the currency futures basis. Table VIII presents the empirical estimates of equation (7) for each currency. The ARMA order is found to be $(3,0)$ in all equations according to the Schwartz information criterion. Except for some evidence for the $\mathrm{CD}$ and BP, for no other currency is there a systematic relationship between realized spot forecast error and the proxies for market risk. For the $\mathrm{CD}$ and $\mathrm{BP}$ spot forecast error equations only the dividend yield is statistically significant at the 10 and 5 per cent levels, respectively, and it enters negatively. These findings suggest that if the systematic risk factors are associated with the expected change in the spot price, this is not evident in the behavior of the realized change in the spot price. The factors in question relate to the currency futures basis through the expected time-varying risk premium component of the basis as opposed to the expected spot forecast error component. These results on the currency futures basis are thus consistent with the evidence provided by Hodrick and Srivastava (1987), Bessembinder and Chan (1992), and McCurdy and Morgan (1992) regarding the presence of risk premia in currency futures pricing. 


\section{Conclusions}

This paper establishes the existence of time-varying risk premia in the currency futures basis and demonstrates that these risk premia may be forecast using three common variables (dividend yield, default spread, and term spread) that have previously been shown to possess forecast power for returns in equity and bond markets. The relationship between risk premia in the currency futures basis and systematic risk depends upon the source of risk, but it is robust across currencies. The currency futures basis varies positively with riskiness in the stock market and negatively with riskiness in the bond market. As these associations cannot be attributed to the expected spot forecast error component of the currency futures basis, the evidence establishes the presence of time-varying risk premia in the currency futures basis while are related to U.S. macroeconomic risks. These results also suggest that multifactor models may be needed to value currency futures contracts, and highlight the commonalities across currency markets.

This study can be extended in at least two ways. First, a complete study of systematic risk factors in currency futures basis must also account for common risk factors associated with governmental/monetary intervention risks. ${ }^{9}$ And second, simultaneous modeling of the entire complex of foreign exchange futures basis and implementation of a Factor-ARCH model may provide additional insights into the common variation of futures basis across currencies. These issues await future research. 


\section{References}

Bailey, W. and K. C. Chan (1993), Macroeconomic Influences and the Variability of the Commodity Futures Basis, Journal of Finance, 555-573.

Bessembinder, H. and K. C. Chan (1992), Time-varying Risk Premia and Forecastable Returns in Futures Markets, Journal of Financial Economics, 32, 169-193.

Berndt, E. K., B. H. Hall, R. E. Hall, and J. A. Hausman (1974), Estimation and Inference in Nonlinear Structural Models, Annals of Economic and Social Measurement, 653-665.

Bollerslev, T. and R.F. Engle (1993), Common Persistence in Conditional Variances, Econometrica, 61:1, 167-186.

Branson, W. A. (1969), The Minimum Covered Interest Differential Needed for International Arbitrage Activity, Journal of Political Economy, 77, 1028-1035.

Chen, N. (1991), Financial Investment Opportunities and the Macroeconomy, Journal of Finance, 529-554.

Cornell, B. and M. Reinganum (1981), Forward and Futures Prices: Evidence from the Foreign Exchange Markets, Journal of Finance, 36, 1035-1045.

Cosander, P. A. and B. R. Laing (1981), Interest Rate Parity Tests: Switzerland and Some Major Western Countries, Journal of Banking and Finance, 5, 187-200.

Dickey, D. and W. Fuller (1981), Likelihood Ratio Statistics for Autoregressive Time Series with a Unit Root, Econometrica 49, 1057-1072.

Diebold, F. X. (1986), Testing for Serial Correlation in the Presence of ARCH, Proceeedings of the American Statistical Association, Business and Economic Statistics Section, 323-328, Washington, D. C: American Statistical Association.

Engle, R. F. (1982), Autoregressive Conditional Heteroscedasticity with Estimates of the Variance of United Kingdom Inflation, Econometrica, 50, 987-1008.

Fama, E. F. and K. R. French (1988a), Business Conditions and Expected Returns on Stocks and Bonds, Journal of Financial Economics, 25, 23-50.

(1988b), Dividend Yields and Expected Stock Returns, Journal of Financial Economics, 22, 3-25.

(1993), Common Risk Factors in the Returns on Stocks and Bonds, Journal of Financial Economics, 33, 3-56.

Frankel, J. (1991), Quantifying International Capital Mobility in the 1990s, in D. Bernheim and J. Shoven, eds. National Saving and Economic Performance, Chicago, University of Chicago Press, 227-260.

Fratianni, M. and L. M. Wakeman (1982), The Law of One Price in the Eurocurrency Market, Journal of International Money and Finance, 1, 307-323. 
Frenkel, J. A. and R. M. Levich (1975), Covered Interest Arbitrage: Unsupported Profits?, Journal of Political Economy, 85, 1209-1226.

(1977), Transactions Costs and Interest Arbitrage: Tranquil versus Turbulent Periods, Journal of Political Economy, 83, 325-338.

Fuller, W. (1976), Introduction to Statistical Time Series. New York: Wiley.

Harvey, C. R. and R. D. Huang (1991), Volatility in the Foreign Currency Futures Market, Review of Financial Studies, 4, 543-569.

Hodrick, R. J. and S. Srivastava (1987), Foreign Currency Futures, International Journal of Forecasting, 22, 1-24.

Hsieh, D. A. (1993), Using Non-linear Methods to Search for Risk Premia in Currency Futures, Journal of International Economics, 35, 113-132.

Keim, D. and R. Stambaugh (1986), Predicting Returns in the Stock and Bond Markets, Journal of Financial Economics, 17, 357-390.

Kwiatkowski, D., P. C. B. Phillips, P. Schmidt, and Y. Shin (1992), Testing the Null Hypothesis of Stationarity against the Alternative of a Unit Root: How Sure are we that Economic Time Series have a Unit Root?, Journal of Econometrics, 54, 159-178.

Marston, R. C. (1976), Interest Arbitrage in the Euro-Currency Markets, European Economic Review, 7, 1-13.

McCallum, B. (1994), A Reconsideration of the Uncovered Interest Parity Relationship,Journal of Monetary Economics, 33, 105-132.

McCurdy, T. H. and J. G. Morgan (1992), Evidence of Risk Premiums in Foreign Currency Futures Markets, Review of Financial Studies, 5, 65-83.

Newey, W. and K. West (1987), A Simple Positive Definite Heteroskedastic and Autocorrelation Consistent Covariance Matrix, Econometrica 55, 703-708.

Phillips, P. C. B. (1987), Time Series Regression with a Unit Root, Econometrica, 55, 277-301. and P. Perron (1988), Testing for Unit Roots in Time Series Regression, Biometrika, 75, 335-346.

Taylor, M. P. (1987), Covered Interest Parity: A High-Frequency, High-Quality Data Study, Economica, 54, 429-438. (1989), Covered Interest Arbitrage and Market Turbulence, Economic Journal, 99, 376391. 
Table I: Autocorrelations and Summary Statistics for Currency Futures Basis

\begin{tabular}{lccccc}
\hline Statistics & CD & DM & BP & SF & JY \\
\hline$\rho_{1}$ & 0.66 & 0.71 & 0.72 & 0.72 & 0.64 \\
$\rho_{2}$ & 0.60 & 0.65 & 0.71 & 0.67 & 0.56 \\
$\rho_{3}$ & 0.75 & 0.74 & 0.75 & 0.78 & 0.65 \\
$\rho_{4}$ & 0.48 & 0.54 & 0.61 & 0.59 & 0.46 \\
$\rho_{5}$ & 0.50 & 0.51 & 0.58 & 0.55 & 0.41 \\
$\rho_{6}$ & 0.64 & 0.57 & 0.61 & 0.64 & 0.43 \\
$\rho_{7}$ & 0.44 & 0.41 & 0.52 & 0.46 & 0.27 \\
$\rho_{8}$ & 0.48 & 0.38 & 0.46 & 0.42 & 0.18 \\
$\rho_{9}$ & 0.57 & 0.47 & 0.54 & 0.53 & 0.27 \\
$\rho_{10}$ & 0.37 & 0.34 & 0.42 & 0.37 & 0.16 \\
$\rho_{11}$ & 0.37 & 0.30 & 0.36 & 0.33 & 0.12 \\
$\rho_{12}$ & 0.39 & 0.40 & 0.44 & 0.45 & 0.23 \\
Mean $(\mu)$ & $-0.524 \mathrm{E}-2$ & $0.713 \mathrm{E}-2$ & $-0.733 \mathrm{E}-2$ & $0.103 \mathrm{E}-2$ & $0.781 \mathrm{E}-2$ \\
Std. Dev. & $(-12.961)$ & $(9.476)$ & $(-9.709)$ & $(11.229)$ & $(11.842)$ \\
\hline
\end{tabular}

Notes:

The sample period is January 1982 to December 1991. The basis equals $\left(F_{t}-S_{t}\right) / S_{t}$ where $S(t)$ is the currency spot rate at the beginning of the month and $F_{t}$ is the contemporaneous price for the futures contract with maturity of approximately three months. Spot and futures rates are opening bid prices for the Canadian dollar (CD), Deutsche mark (DM), British pound (BP), Swiss franc (SF), and the Japanese yen (JY). $t$-statistics for the hypothesis that $\mu=0$ are given in parentheses. 
Table II: Tests for Serial Independence in the Currency Futures Basis

\begin{tabular}{lccccc}
\hline Statistic & CD & DM & BP & SF & JY \\
\hline $\mathrm{Q}(1)$ & 7.674 & 29.896 & 20.752 & 15.638 & 9.598 \\
$\mathrm{Q}(2)$ & 14.668 & 56.869 & 38.890 & 30.719 & 18.495 \\
$\mathrm{Q}(4)$ & 27.768 & 109.48 & 67.901 & 60.426 & 34.278 \\
$\mathrm{Q}(6)$ & 39.647 & 155.64 & 92.000 & 89.888 & 49.210 \\
$\mathrm{Q}(12)$ & 69.671 & 243.95 & 142.88 & 157.15 & 79.415 \\
ARCH(1) & 33.413 & 13.261 & 16.085 & 33.229 & 26.439 \\
ARCH(2) & 39.470 & 18.450 & 27.981 & 39.043 & 38.106 \\
ARCH(4) & 76.143 & 38.144 & 62.075 & 71.192 & 75.442 \\
ARCH(6) & 77.374 & 37.607 & 61.245 & 77.756 & 56.762 \\
ARCH(12) & 75.808 & 51.200 & 62.420 & 71.744 & 47.218 \\
\hline
\end{tabular}

Notes:

The sample period is January 1982 to December 1991. See Table I for definition of series.

$\mathrm{Q}(\mathrm{k})$ : Heteroscedasticity-adjusted Box-Pierce test statistic for autocorrelation of order k (Diebold, 1986). ARCH(k) : Engle's (1982) LM test for ARCH of order k.

All test statistics are significant at the $1 \%$ level. 
Table III: Phillips-Perron Unit Root Tests on Currency Futures Basis

\begin{tabular}{lcccccccc}
\hline Test Statistic & CD & DM & BP & SF & JY & DY & DEF & TERM \\
\hline$Z\left(\alpha^{\prime}\right)$ & -11.29 & -12.36 & -12.17 & -9.43 & -13.90 & -0.90 & 141.61 & -112.60 \\
$Z\left(t \alpha^{\prime}\right)$ & -2.45 & -2.56 & -2.48 & -2.28 & -2.89 & -1.86 & -13.55 & -9.78 \\
$Z\left(a^{*}\right)$ & -44.66 & -29.94 & -31.69 & -29.17 & -43.93 & -5.16 & 140.23 & -109.51 \\
$Z\left(t_{a^{*}}\right)$ & -5.09 & -3.90 & -4.22 & -3.90 & -5.02 & -2.22 & -13.63 & -10.04 \\
$Z\left(\phi_{1}\right)$ & 13.02 & 7.68 & 8.94 & 7.67 & 12.69 & 3.57 & 92.83 & 50.47 \\
$Z\left(a^{\sim}\right)$ & -86.24 & -86.36 & -93.76 & -116.06 & -82.18 & -8.69 & 138.55 & -109.05 \\
$Z\left(t_{a}\right)$ & -7.29 & -7.30 & -7.68 & -8.76 & -7.07 & -2.28 & -13.75 & -10.01 \\
$Z\left(\phi_{2}\right)$ & 17.80 & 17.96 & 19.77 & 25.80 & 16.76 & 2.80 & 63.10 & 33.45 \\
$Z\left(\phi_{3}\right)$ & 26.83 & 27.03 & 29.79 & 38.84 & 25.26 & 4.13 & 95.54 & 50.63 \\
\hline
\end{tabular}

Notes:

The sample period is January 1982 to December 1991. DY is the dividend yield on the SP500 portfolio. DEF is the net return from investing in long-term corporate bonds rather than long-term government bonds of equal maturity. TERM is the net return from investing in long-term government bonds rather than one-month U.S. Treasury bills. See Table I for definition of the rest of the series. The nine different statistics all test for a unit root in the univariate time-series representation for each of the series against a stationary or trend-stationary alternative. In constructing the test statistics the order of serial correlation allowed is six. Inference is robust to the order of serial correlation allowed. The lag window suggested by Newey and West (1987) is used to ensure positive semidefiniteness. For more details on the tests see Phillips (1987), and Phillips and Perron (1988). The critical values are as follows (Fuller (1976), and Dickey and Fuller (1981)) with rejections of the null hypothesis indicated by large absolute values of the statistics:

\begin{tabular}{lccccccccc}
\hline $\begin{array}{l}\text { Critical } \\
\text { Values }\end{array}$ & $Z\left(\alpha^{\prime}\right)$ & $Z\left(t_{\alpha^{\prime}}\right)$ & $Z\left(a^{*}\right)$ & $Z\left(t_{a^{*}}\right)$ & $Z\left(\phi_{1}\right)$ & $Z\left(a^{\sim}\right)$ & $Z\left(t_{a^{\sim}}\right)$ & $Z\left(\phi_{2}\right)$ & $Z\left(\phi_{3}\right)$ \\
\hline $10 \%$ & -5.7 & -1.62 & -11.3 & -2.57 & 3.78 & -18.3 & -3.12 & 4.03 & 5.34 \\
$5 \%$ & -8.1 & -1.95 & -14.1 & -2.86 & 4.59 & -21.8 & -3.41 & 4.68 & 6.25 \\
$2.5 \%$ & -10.5 & -2.23 & -16.9 & -3.12 & 5.38 & -25.1 & -3.66 & 5.31 & 7.16 \\
$1 \%$ & -13.8 & -2.58 & -20.7 & -3.43 & 6.43 & -29.5 & -3.96 & 6.09 & 8.27 \\
\hline
\end{tabular}


Table IV: Kwiatkowski-Phillips-Schmidt-Shin (KPSS) Unit Root Tests on Currency Futures Basis

\begin{tabular}{lcccccccc}
\hline Test & CD & DM & BP & SF & JY & DY & DEF & TERM \\
\hline$\eta_{\mu}$ & 1.045 & 1.161 & 1.260 & 1.390 & 0.806 & 1.258 & 0.107 & 0.084 \\
$\eta_{\tau}$ & 0.091 & 0.236 & 0.070 & 0.164 & 0.131 & 0.274 & 0.056 & 0.056 \\
\hline
\end{tabular}

Notes:

The sample period is January 1982 to December 1991. See Tables I and III for definition of the series. $T^{-2} \sum^{T} S_{t}^{2}$

$\eta_{\mu}=\frac{T^{-2} \sum_{t=1} S_{t}^{2}}{s^{2}(l)}$ is the test statistic for the null hypothesis of level stationarity, where $S_{t}=\sum_{i=1}^{t} e_{i}, t=1,2, \ldots, T$ (partial sum process of the residuals) with $\left\{e_{t}\right\}_{1}^{T}$ being the residuals from the regression of the series on an intercept, and $s^{2}(l)$ is a consistent estimate of the "long-run variance". The estimator used here is of the form $s^{2}(l)=T^{-1} \sum_{t=1}^{T} e_{t}^{2}+2 T^{-1} \sum_{s=1}^{l} w(s, l) \sum_{t=s+1}^{T} e_{t} e_{t-s}$

where $w(s, l)$ is an optimal lag window. The order of serial correlation allowed is six. Inference is generally robust to the order of serial correlation allowed. The lag window suggested by Newey and West (1987) is used to ensure positive semidefiniteness of $s^{2}(l)$. The test statistic for the null hypothesis of trend stationarity, $\eta_{\tau}$, differs from $\eta_{\mu}$ in that the series of residuals $\left\{e_{t}\right\}_{1}^{T}$ is obtained from regressing the series on an intercept and time trend. Both tests are upper-tail tests and the critical values are as follows (Kwiatkowski et al. (1992)):

\begin{tabular}{lcccc}
\hline Critical Values & $10 \%$ & $5 \%$ & $2.5 \%$ & $1 \%$ \\
\hline$\eta_{\mu}$ & 0.347 & 0.463 & 0.574 & 0.739 \\
$\eta_{\tau}$ & 0.119 & 0.146 & 0.176 & 0.216 \\
\hline
\end{tabular}


Table V: Contemporaneous Correlations of Currency Futures Basis

\begin{tabular}{llllll}
\hline & CD & DM & BP & SF & JY \\
\hline CD & 1.000 & & & & \\
DM & 0.507 & 1.000 & & & \\
BP & 0.758 & 0.710 & 1.000 & & \\
SF & 0.535 & 0.934 & 0.775 & 1.000 & \\
JY & 0.375 & 0.815 & 0.637 & 0.819 & 1.000 \\
\hline
\end{tabular}

Notes:

See Table I for definition of the series. 
Table VI: Principal Component Analysis of the Currency Futures Basis

\begin{tabular}{lcc}
\hline & \multicolumn{2}{c}{$h^{2}$ for Factor Analysis } \\
\hline & 1 Factor & 2 Factors \\
\hline CD & 0.423 & 0.647 \\
DM & 0.855 & 0.903 \\
BP & 0.736 & 0.835 \\
SF & 0.905 & 0.932 \\
JY & 0.655 & 0.726 \\
\hline Notes: & &
\end{tabular}

The $h^{2}$ is the final communality estimate of a particular currency basis series and represents the fraction of its variance that is related to the common factors. 
Table VII: Maximum-Likelihood Estimates of the ARMAX-GARCH Model for the Currency Futures Basis

$$
\begin{gathered}
100 \cdot F B_{i, t}=\alpha_{i 0}+\alpha_{i 1} D Y_{t-1}+\alpha_{i 2} D E F_{t-1}+\alpha_{i 3} \text { TERM }_{t-1}+\varepsilon_{i, t} \\
\varepsilon_{i, t}=\beta_{i}(L) \varepsilon_{i, t}+\gamma_{i}(L) u_{i, t}, \beta_{i}(L)=\sum_{l=1}^{p} \beta_{i l} L^{l}, \gamma_{i}(L)=\sum_{l=1}^{q} \gamma_{i l} L^{l} \\
\operatorname{Var}\left(u_{i, t} \mid \Omega_{t}\right) \equiv \sigma_{i, t}^{2}=\omega_{i}+\delta_{i i} u_{i, t-1}^{2}+\varsigma_{i i} \sigma_{i, t-1}^{2}
\end{gathered}
$$

\begin{tabular}{lccccc}
\hline Coefficients & $\mathrm{CD}$ & $\mathrm{DM}$ & $\mathrm{BP}$ & $\mathrm{SF}$ & $\mathrm{JY}$ \\
\hline$\alpha_{i 0}$ & -0.215 & -0.659 & -1.521 & -0.124 & 0.344 \\
& $(-0.252)$ & $(-9.491)^{\mathrm{a}}$ & $(-3.647)^{\mathrm{a}}$ & $(-0.238)$ & $(0.636)$ \\
$\alpha_{i 1}$ & -0.187 & 0.401 & 0.300 & 0.360 & 0.064 \\
& $(-1.984)^{\mathrm{b}}$ & $(292.924)^{\mathrm{a}}$ & $(6.619)^{\mathrm{a}}$ & $(3.418)^{\mathrm{a}}$ & $(0.656)$ \\
$\alpha_{i 2}$ & -6.790 & -4.325 & 2.686 & -9.237 & -4.361 \\
& $(-5.310)^{\mathrm{a}}$ & $(-2.729)^{\mathrm{a}}$ & $(3.419)^{\mathrm{a}}$ & $(-2.544)^{\mathrm{b}}$ & $(-4.189)^{\mathrm{a}}$ \\
$\alpha_{i 3}$ & -3.312 & -1.528 & -1.509 & -1.826 & -2.902 \\
& $(-11.595)^{\mathrm{a}}$ & $(-1.735)^{\mathrm{c}}$ & $(-1.665)^{\mathrm{c}}$ & $(-2.025)^{\mathrm{b}}$ & $(-2.690)^{\mathrm{a}}$ \\
$\omega_{i}$ & 0.006 & 0.017 & 0.012 & 0.005 & 0.039 \\
& $(1.197)$ & $(3.743)^{\mathrm{a}}$ & $(1.344)$ & $(2.219)^{\mathrm{b}}$ & $(1.526)$ \\
$\delta_{i i}$ & 0.147 & 0.272 & 0.143 & 0.059 & 0.151 \\
& $(1.166)$ & $(1.371)$ & $(1.233)$ & $(1.217)$ & $(0.762)$ \\
$\varsigma_{i i}$ & 0.696 & 0.613 & 0.773 & 0.933 & 0.516 \\
& $(3.348)^{\mathrm{a}}$ & $(3.760)^{\mathrm{a}}$ & $(6.185)^{\mathrm{a}}$ & $(23.167)^{\mathrm{a}}$ & $(1.707)^{\mathrm{c}}$ \\
Log-Lik. & 117.442 & 55.769 & 55.136 & 47.248 & 65.447 \\
$\mathrm{R}^{2}$ & 0.756 & 0.760 & 0.749 & 0.786 & 0.736 \\
$\mathrm{Q}(6)$ & 6.989 & 13.576 & 4.407 & 12.442 & 2.165 \\
& $(0.321)$ & $(0.034)$ & $(0.621)$ & $(0.052)$ & $(0.903)$ \\
$\mathrm{Q}^{2}(6)$ & 4.259 & 11.526 & 7.311 & 12.806 & 6.765 \\
& $(0.641)$ & $(0.073)$ & $(0.293)$ & $(0.046)$ & $(0.343)$ \\
Unit Root Tests for $\sigma_{t}^{2}$ & & & & \\
PP : Z $\left(a^{\sim}\right)$ & -28.689 & -35.146 & -10.946 & 2.412 & -53.814 \\
KPSS : $\left(\eta_{t}\right)$ & 0.061 & 0.291 & 0.177 & 0.219 & 0.150 \\
\hline
\end{tabular}

Notes:

t-statistics are given in parentheses for the coefficient estimates. Marginal significance levels are given in parentheses for the rest. The $\operatorname{ARMA}(p, q)$ representations for the currency futures basis are selected based on the Schwartz criterion and are of the following order for the CD, DM, BP, SF, and JY futures basis, respectively: $(6,4),(3,3),(3,3),(5,5)$, and $(3,3)$. To conserve space, the ARMA coefficient estimates are not presented. The $\mathrm{Q}(6)$ and $\mathrm{Q}^{2}(6)$ are the Box-Pierce test statistics for autocorrelation of order 6 in the standardized and squared standardized residuals, respectively. The order of serial correlation allowed in the Phillips-Perron (PP) and Kwiatkowski-Phillips-Schmidt-Shin (KPSS) unit root tests is six. a, b, c denote significance at the 1\%, 5\%, and $10 \%$ levels, respectively. 
Table VIII: Maximum-Likelihood Estimates of the ARMAX-GARCH Model for the Realized Spot Forecast Error Equations

$$
\begin{gathered}
100 \cdot\left(S_{t+1}-S_{t}\right) / S_{t}=\vartheta_{i 0}+\vartheta_{i 1} D Y_{t-1}+\vartheta_{i 2} D E F_{t-1}+\vartheta_{i 3} \operatorname{TERM}_{t-1}+\eta_{i, t} \\
\eta_{i, t}=\lambda_{i}(L) \eta_{i, t}+\mu_{i}(L) v_{i, t}, \lambda_{i}(L)=\sum_{l=1}^{p} \lambda_{i l} L^{l}, \mu_{i}(L)=\sum_{l=1}^{q} \mu_{i l} L^{l} \\
\operatorname{Var}\left(v_{i, t} \mid \Omega_{t}\right) \equiv \sigma_{i, t}^{2}=o_{i}+\pi_{i i} v_{i, t-1}^{2}+\tau_{i i} \sigma_{i, t-1}^{2}
\end{gathered}
$$

\begin{tabular}{lccccc}
\hline Coefficients & $\mathrm{CD}$ & $\mathrm{DM}$ & $\mathrm{BP}$ & $\mathrm{SF}$ & $\mathrm{JY}$ \\
\hline$\alpha_{i 0}$ & 2.320 & 7.485 & 8.316 & 7.740 & 8.561 \\
& $(1.936) \mathrm{c}$ & $(1.727) \mathrm{c}$ & $(2.148) \mathrm{b}$ & $(1.648)^{\mathrm{c}}$ & $(1.771)^{\mathrm{c}}$ \\
$\vartheta_{i 1}$ & -0.514 & -1.657 & -2.045 & -1.812 & -1.821 \\
& $(-1.712) \mathrm{c}$ & $(-1.617)$ & $(-2.298) \mathrm{b}$ & $(-1.544)$ & $(-1.576)$ \\
$\vartheta_{i 2}$ & 17.261 & -8.567 & 0.765 & 2.898 & -7.227 \\
& $(1.467)$ & $(-0.276)$ & $(0.031)$ & $(0.086)$ & $(-0.226)$ \\
$\vartheta_{i 3}$ & 2.912 & -10.107 & -8.360 & 1.309 & -0.801 \\
& $(0.637)$ & $(-0.857)$ & $(-0.673)$ & $(0.099)$ & $(-0.057)$ \\
$o_{i}$ & 1.676 & 1.934 & 1.488 & 2.425 & 7.309 \\
& $(1.903) \mathrm{c}$ & $(1.245)$ & $(1.936) \mathrm{c}$ & $(1.580)$ & $(1.490)$ \\
$\pi_{i i}$ & 0.346 & 0.021 & 0.011 & 0.194 & 0.105 \\
& $(1.408)$ & $(0.375)$ & $(0.237)$ & $(1.384)$ & $(0.901)$ \\
$\tau_{i i}$ & 0.000 & 0.879 & 0.916 & 0.709 & 0.545 \\
& $(0.005)$ & $(8.431) \mathrm{a}$ & $(12.625) \mathrm{a}$ & $(4.940) \mathrm{a}$ & $(2.027) \mathrm{b}$ \\
Log-Lik. & -102.620 & -223.51 & -224.145 & -231.400 & -232.333 \\
$\mathrm{R}^{2}$ & 0.447 & 0.562 & 0.552 & 0.539 & 0.514 \\
$\mathrm{Q}(6)$ & 19.496 & 9.218 & 11.961 & 10.815 & 13.497 \\
$\mathrm{Q}^{2}(6)$ & $(0.003)$ & $(0.161)$ & $(0.062)$ & $(0.094)$ & $(0.035)$ \\
& 3.597 & 1.446 & 4.240 & 2.264 & 5.763 \\
& $(0.730)$ & $(0.963)$ & $(0.644)$ & $(0.893)$ & $(0.450)$ \\
\hline
\end{tabular}

Notes:

t-statistics are given in parentheses for the coefficient estimates. Marginal significance levels are given in parentheses for the rest. The $\operatorname{ARMA}(p, q)$ representations for the currency futures basis are selected based on the Schwartz criterion and are of order $(3,0)$ for all equations. To conserve space, the ARMA coefficient estimates are not presented. The $\mathrm{Q}(6)$ and $\mathrm{Q}^{2}(6)$ are the Box-Pierce test statistics for autocorrelation of order 6 in the standardized and squared standardized residuals, respectively. a, b, c denote significance at the $1 \%$, 5\%, and $10 \%$ levels, respectively. 
$\S$ Boston College and West Virginia University, respectively. We acknowledge the helpful comments of Robert G. Murphy, participants in the 1994 North American Summer Meetings of the Econometric Society and two anonymous referees. The usual disclaimer applies. Please address correspondence to Baum at Department of Economics, Boston College, Chestnut Hill, MA 02167, 617552 3673, fax 617552 2308, email baum@bc.edu.

1 Other factors besides transaction costs that could be responsible for deviations from the CIP relationship are information costs, tax laws that discriminate by country of residence, capital controls, default risk, and risk of future capital controls.

2 The forward rate is usually used in the CIP condition. It is well known that futures contracts differ in several ways from forward contracts. Forward prices are quoted in an interbank market for delivery at a fixed time of maturity that is typically one, three, six, or twelve months. Futures prices are quoted at an organized exchange such as the International Monetary Market (IMM) in Chicago. Contracts are traded for delivery on the third Wednesday of March, June, September, and December; there are typically four contracts outstanding at a point in time. Futures contracts are also marked to market daily which induces a theoretical reason why forward prices and futures prices for delivery on the same day in the future may differ. Although in theory there may be a difference between forward prices and futures prices for delivery on the same day in the future, the empirical work by Cornell and Reinganum (1981) found very little difference between the two speculative prices.

3 The correlations between futures basis and interest rate differentials in the monthly data range from 0.70 (for the yen) to 0.88 for the Swiss franc. The fact that these positive correlations are less than perfect can be attributed to some of the reasons mentioned in footnote 1.

4 Following the literature, the "relative basis" is used in the empirical analysis, that is, both sides of equation (2) are scaled by $S_{t}$.

5 The flat price is the average of the bond's bid and ask prices, plus the accrued interest. 
6 In the equivalent equation Bailey and Chan also included the domestic interest rate when analyzing the commodity futures basis. By analogy, one would include the interest rate differential in equation (6). Doing so, however, amounts to testing for the CIP condition using the regression method, which holds true for the major currencies (Branson (1969), Marston (1976), Cosander and Laing (1981), Fratianni and Wakeman (1982), Frankel (1991)). Statistical significance of any of the other variables in such a formulation would be associated with any of the following: mark-tomarket effects, measurement errors, transaction costs. The interest rate differential was included in equation (6); consistent with the CIP relationship, the coefficient for the interest rate differential was close to unity and for the other variables it was statistically insignificant. The reason for including the interest rate when analyzing the commodity futures basis is that, in addition to the interest foregone in storing a commodity, there are other idiosyncratic factors to explain variations in the commodity futures basis. Although such elements may play an important role in the basis for agricultural commodities, commodity-specific factors are not relevant in the foreign exchange markets. The CIP relationship is an arbitrage condition in the international bond market and must hold true.

7 The $R^{2}$ s in these equations are much higher than those reported in Bailey and Chan-quite plausibly because the dynamics of the error term are explicitly modeled, which adds explanatory power.

8 Currency spot and futures rates for the SF could be copersistent with some other copersistence vector.

9 We thank an anonymous referee for offering this suggestion. 
Figure 1: Currency Futures Basis

Figure 2: Correlograms for Currency Futures Basis

Figure 3: Dividend Yield on the SP500 Portfolio

Figure 4: Bond Default and Term Spreads 
Figure 1: Currency Futures Basis, 1982-1991

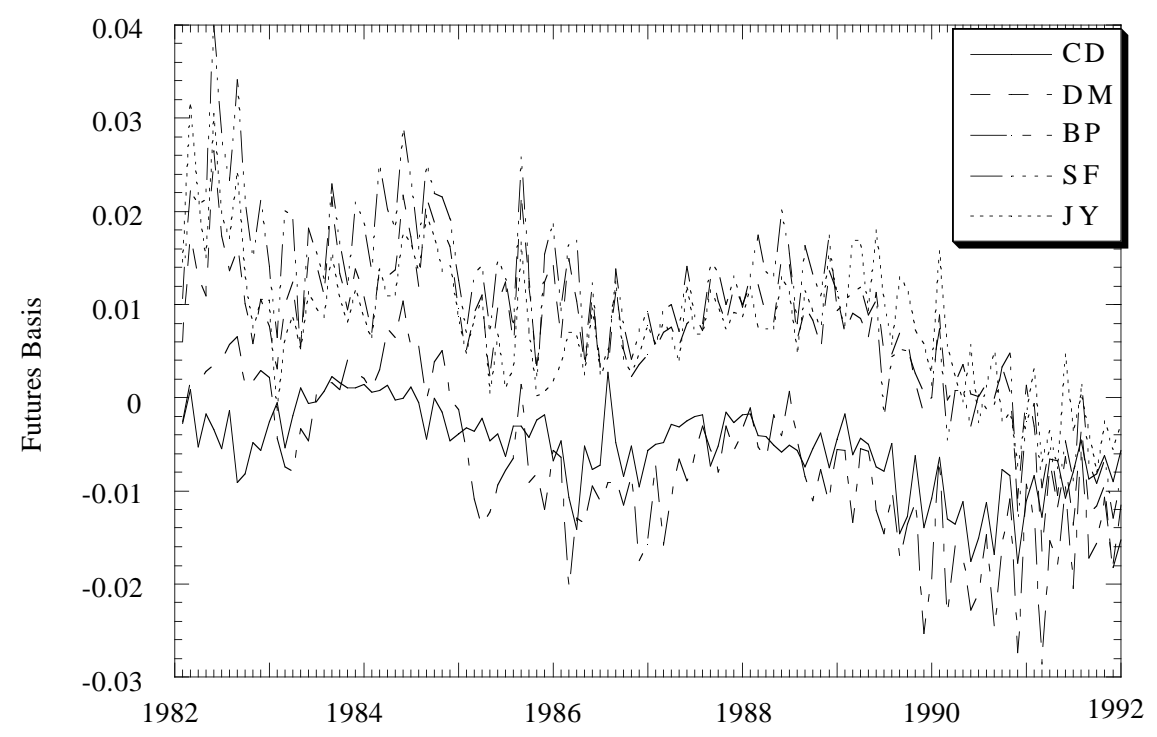

Figure 3: Dividend Yield on the SP500 Portfolio

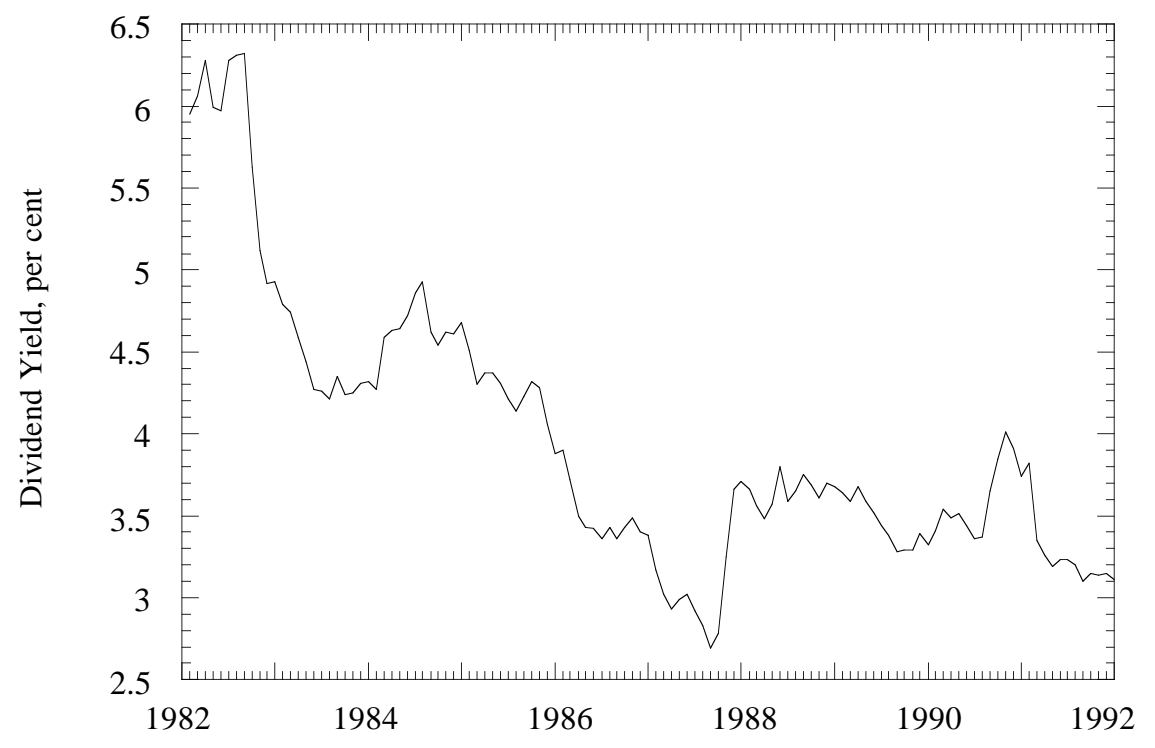

Figure 2: Correlog

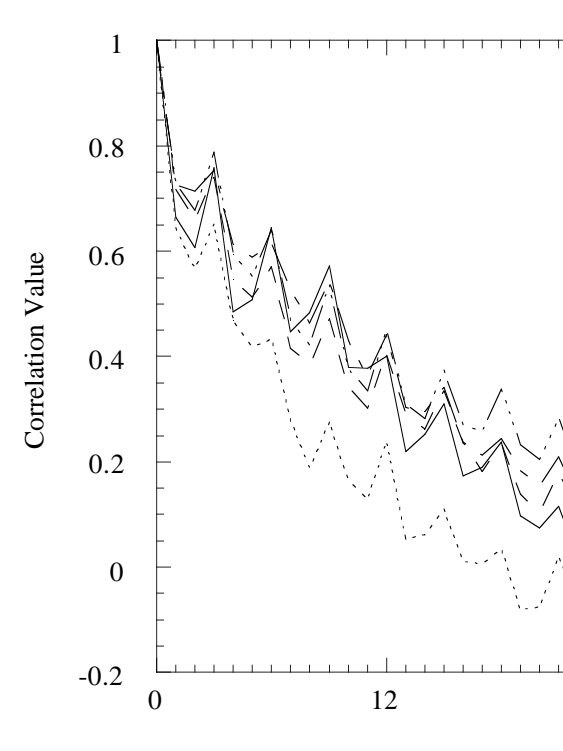

Figure 4: Bo

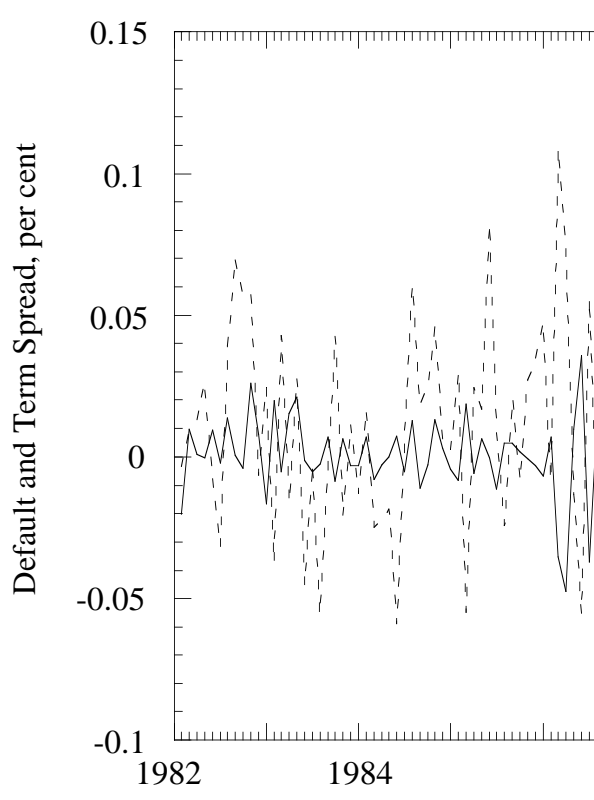

